\title{
Grass-like plants release general volatile cues attractive for gravid Anopheles gambiae sensu stricto mosquitoes
}

Getachew E. Bokore ${ }^{1,2,3^{*+}} \mathbb{D}$, Linus Svenberg ${ }^{4^{*}+}$, Richard Tamre ${ }^{1,2}$, Patrick Onyango ${ }^{2}$, Tullu Bukhari ${ }^{1}$, Åsa Emmer ${ }^{4}$ and Ulrike Fillinger ${ }^{1}$

\begin{abstract}
Background: Understanding the ecology and behaviour of disease vectors, including the olfactory cues used to orient and select hosts and egg-laying sites, are essential for the development of novel, insecticide-free control tools. Selected graminoid plants have been shown to release volatile chemicals attracting malaria vectors; however, whether the attraction is selective to individual plants or more general across genera and families is still unclear.

Methods: To contribute to the current evidence, we implemented bioassays in two-port airflow olfactometers and in large field cages with four live graminoid plant species commonly found associated with malaria vector breeding sites in western Kenya: Cyperus rotundus and C. exaltatus of the Cyperaceae family, and Panicum repens and Cynodon dactylon of the Poaceae family. Additionally, we tested one Poaceae species, Cenchrus setaceus, not usually associated with water. The volatile compounds released in the headspace of the plants were identified using gas chromatography/mass spectrometry.
\end{abstract}

Results: All five plants attracted gravid vectors, with the odds of a mosquito orienting towards the choice-chamber with the plant in an olfactometer being 2-5 times higher than when no plant was present. This attraction was maintained when tested with free-flying mosquitoes over a longer distance in large field cages, though at lower strength, with the odds of attracting a female 1.5-2.5 times higher when live plants were present than when only water was present in the trap. Cyperus rotundus, previously implicated in connection with an oviposition attractant, consistently elicited the strongest response from gravid vectors. Volatiles regularly detected were limonene, $\beta$-pinene, $\beta$-elemene and $\beta$-caryophyllene, among other common plant compounds previously described in association with odour-orientation of gravid and unfed malaria vectors.

Conclusions: The present study confirms that gravid Anopheles gambiae sensu stricto use chemical cues released from graminoid plants to orientate. These cues are released from a variety of graminoid plant species in both the Cyperaceae and Poaceae family. Given the general nature of these cues, it appears unlikely that they are exclusively used for the location of suitable oviposition sites. The utilization of these chemical cues for attract-and-kill trapping

*Correspondence: egetachew@icipe.org; svenberg@kth.se

${ }^{\dagger}$ Getachew E. Bokore and Linus Svenberg contributed equally to this

study

${ }^{2}$ School of Physical and Biological Sciences, Department of Zoology,

Maseno University, Maseno, Kenya

${ }^{4}$ Analytical Chemistry, Div. of Applied Physical Chemistry, Dept.

of Chemistry, KTH Royal Institute of Technology, Stockholm, Sweden

Full list of author information is available at the end of the article

(c) The Author(s) 2021. Open Access This article is licensed under a Creative Commons Attribution 4.0 International License, which permits use, sharing, adaptation, distribution and reproduction in any medium or format, as long as you give appropriate credit to the original author(s) and the source, provide a link to the Creative Commons licence, and indicate if changes were made. The images or other third party material in this article are included in the article's Creative Commons licence, unless indicated otherwise in a credit line to the material. If material is not included in the article's Creative Commons licence and your intended use is not permitted by statutory regulation or exceeds the permitted use, you will need to obtain permission directly from the copyright holder. To view a copy of this licence, visit http://creativecommons.org/licenses/by/4.0/. The Creative Commons Public Domain Dedication waiver (http://creativeco mmons.org/publicdomain/zero/1.0/) applies to the data made available in this article, unless otherwise stated in a credit line to the data. 
strategies must be explored under natural conditions to investigate their efficiency when in competition with complex interacting natural cues.

Keywords: Attractants, Gravid mosquitoes, Malaria, Graminoid plants, Olfactometer, Plant volatiles, Semi-field, Vector control, Attract-and-kill

\section{Background}

Mosquitoes use visual, olfactory, and tactile cues for survival and reproduction in a complex environment [1]. Understanding the ecology and behaviour of disease vectors, including the olfactory cues used to orient and select hosts and egg-laying sites, is essential for the development of novel, insecticide-free control tools [2-4]. The outdoor behaviour of Afro-tropical malaria vectors has gained increased attention over the past decade, after a realization that interventions targeted at the indoor environment alone will not be sufficient to eliminate malaria from most locations in sub-Saharan Africa [5-7]. Tools that complement long-lasting insecticidal nets (LLINs) and indoor residual sprays (IRS) need to combat physiological insecticide resistance and address behavioural insecticide avoidance such as outdoor feeding and resting $[3,8,9]$. For their reproductive success, malaria vector mosquitoes depend on finding and selecting a suitable aquatic habitat for egg-laying and development of their immature stages [10-12]. The need for an aquatic habitat unites all female vectors irrespective of their feeding and resting behaviour, and degree of resistance to insecticides. This provides an opportunity to target this physiological stage for control. Studying the chemical ecology of the egg-laying behaviour of gravid malaria vectors will increase our knowledge on the sources, role and importance of volatile organic compounds (VOCs) regulating the communications between mosquitoes and their environment and might consequently facilitate the development of novel vector control and surveillance tools [13]. A range of sources for putative, attractive or repellent, chemical oviposition cues have been implicated in the literature for malaria vector mosquitoes, including from conspecific immature stages, predators, competitors, microbes, water, soil, plants and plant-based infusions [14-23].

Emergent vegetation, including graminoid plants, are frequently associated with high numbers of Anopheles larvae in aquatic habitats in ecological larval habitat risk factor surveys [24-29]. The vegetation might provide coverage from predators [30,31], support microbes that contribute indirectly or directly to nutrition of the mosquito immature stages [32-35], and consequently improve survival. It is therefore plausible to hypothesize that cues from habitat-associated vegetation are used by gravid females for location of suitable breeding sites.
It is well documented that plants emit VOCs that play important roles in the plants' interactions with their environments, including insects [36-39]. Graminoid plants found in and around natural aquatic habitats have been suggested to be associated with oviposition site selection of gravid malaria vectors [17, 22, 40-42].

For example, studies have shown that gravid malaria vectors are attracted to headspace volatiles released from wetland rice plants (Oryza sp. [22]) and to volatiles released from pollen of maize (Zea mays [43]) and sugar cane (Saccharum officinarum [44]). The authors of that work suggest that mosquitoes have selectively adapted to habitats dominated by agricultural grasses of the Poaceae family which in turn would suggest that these grasses release a unique odour profile that separates them from native (non-agricultural) grasses.

On the other hand, the grass-like sedges in the Cyperaceae family are frequently indicators of wetlands [45, 46] and have been associated with productive Anopheles breeding sites in a multitude of studies [28, 40, 47]. Cedrol, a sesquiterpene alcohol, was identified from the headspace of aqueous infusions that were made from soil and rhizomes taken from a productive Anopheles habitat, that was densely vegetated by the sedge, Cyperus rotundus. The infusion as well as water treated with synthetic cedrol attracted An. gambiae and An. arabiensis in laboratory, semi-field and field experiments [17, 21]. Plant-based chemical compounds might either be released from roots and submerged plant parts into the water $[36,48]$ of the potential oviposition site or might be released into the air from the emergent parts of the plant $[36,49]$. Cedrol has been identified directly from rhizome extracts of sedges [50] as well as from associated microbes [41].

It is against this background that we set out to contribute to the current knowledge base by further investigating native graminoid plant species from the Cyperaceae and Poaceae families for their potential to attract gravid malaria vectors with the volatiles they release when present as intact plants. The four selected test plant species dominate natural aquatic habitats around the shores of Lake Victoria in western Kenya [40]. For comparison, an ornamental dry-land grass, of the Poaceae family, usually not associated with malaria vector breeding sites was included in the study. The overall aim of this work was to investigate whether chemical cues released from 
graminoid plants result in species- or family-specific volatile profiles and selective responses from gravid $A n$. gambiae, or whether the chemical cues are of a more general nature.

\section{Methods}

Study site

All experiments and plant volatile collections were conducted under ambient climate conditions at the International Centre of Insect Physiology and Ecology (icipe), Thomas Odhiambo Campus (TOC), Mbita $\left(00^{\circ}\right.$ $26^{\prime} 06.19^{\prime \prime}$ S; $34^{\circ} 12^{\prime} 53.13^{\prime \prime}$ E; $1137 \mathrm{~m}$ above sea level), western Kenya. The area is characterized by an equatorial tropical climate with daily average minimum and maximum temperatures ranging from $16{ }^{\circ} \mathrm{C}$ to $28{ }^{\circ} \mathrm{C}$. The chemical analyses of the volatile samples were done at laboratories at KTH Royal Institute of Technology in Stockholm, Sweden.

\section{Gravid mosquito preparation}

Anopheles gambiae sensu stricto (s.s.) Mbita strain insectary-reared mosquitoes were used for all experiments. Mosquitoes were reared under ambient conditions following the protocol described by Okal et al. [51]. Adult mosquitoes were held in $30 \times 30 \times 30 \mathrm{~cm}$ nettingcovered cages at $25-28{ }^{\circ} \mathrm{C}$ and $68-75 \%$ relative humidity in a $12 \mathrm{~h}: 12 \mathrm{~h}$ light/dark photoperiod. Equal numbers of 2-3-day-old adult female and male mosquitoes were transferred into a clean cage and starved for $6 \mathrm{~h}$ starting at 13:00 before they were allowed to feed on a human arm at 19:00 for $15 \mathrm{~min}$. Blood feeding was repeated the next day at 19:00 using the same procedure. After each blood meal, the mosquitoes were provided with $6 \%$ glucose solution ad libitum. A wet towel was placed on top of the cages to provide additional humidity. After the second blood meal, the mosquitoes were kept for another 2 days with access to glucose solution. On the third day, gravid females were selected and used in bioassays.

\section{Preparation of test substrates}

Four graminoid plant species, naturally occurring frequently in malaria vector breeding sites in western Kenya [40], namely the grass-like sedges (Cyperaceae), C. rotundus (nut grass), and C. exaltatus (giant sedge), as well as the true grasses (Poaceae), Panicum repens (torpedo grass) and Cynodon dactylon (Bermuda grass) were collected from wetlands along the shores of Lake Victoria, around Mbita and Rusinga towns, western Kenya. The plants were carefully uprooted and the plants with soil transported to icipe-TOC for bioassays in olfactometers and large field cages, and for volatile collections. A drought-tolerant grass, not native to wetlands and frequently used as ornamental grass in gardens, Cenchrus setaceus (purple fountain grass; Poaceae) was obtained from plant nurseries in Kisumu town and maintained at icipe-TOC. The plants were used only in their nonflowering stage (roots, stems and leaves only) in order to standardize the experiments (flowering plants likely release different odours than non-flowering) and be in the position to have sufficient plant material at any time. In preparation for bioassays, the plants were washed thoroughly using lake water to remove the soil. Fresh plant samples were used for every round of bioassays. A bunch of several individual plants, weighing approximately $350 \mathrm{~g}$, was used for every replicate bioassay.

Soil collected from the habitat where $C$. rotundus was uprooted was used for a preliminary bioassay. The soil was taken from the upper $10 \mathrm{~cm}$ of the habitat and plant material sieved out before use. For each replicate bioassay, $4 \mathrm{~kg}$ of fresh soil was used.

Water was used in all bioassays (4 1 per test substrate), acknowledging that water vapour is a major oviposition attractant [20]. The water originated from Lake Victoria and sediments allowed to settle before the clear supernatant was used for experiments.

A hay-infusion previously shown to be repellent for gravid An. gambiae [21] was prepared for the initial calibration of the olfactometer bioassays. The infusion was prepared by mixing 241 of lake water and $90 \mathrm{~g}$ of hay in a bucket and kept in a dark place with the temperature ranging from $18{ }^{\circ} \mathrm{C}$ to $29^{\circ} \mathrm{C}$ for 3 days before use for the bioassays. Before use, buckets were thoroughly cleaned with odourless soap and allowed to dry under the sun.

\section{Two-port airflow olfactometer bioassays}

Four two-port olfactometers were constructed from galvanized iron sheets (Fig. 1) to test the odour-orientation of gravid An. gambiae s.s. in response to test substrates. The olfactometers were placed in a netting-screened makeshift shed where experiments were run overnight under ambient conditions. The olfactometers had two large substrate holding chambers $(1 \times 0.9 \times 1 \mathrm{~m})$, two trapping chambers made of polyvinyl chloride (PVC) pipes (30 cm long and $10 \mathrm{~cm}$ diameter), a fan and mosquito release chamber $(0.5 \times 0.2 \times 0.3 \mathrm{~m})$. The size of substrate holding chambers was sufficient to carry whole live plants. Mosquitoes were introduced into the release chamber through an opening at the bottom. An electricity-powered fan drew air from the two substrate holding chambers through the holding chamber to the outside. Funnels inserted into the trapping chamber prevented mosquitoes from returning to the release chamber.

Test substrates were placed in both holding chambers. The fan was switched on five minutes before releasing 100 gravid An. gambiae s.s. to the choice chamber at 18:00. The choice made by mosquitoes was recorded 


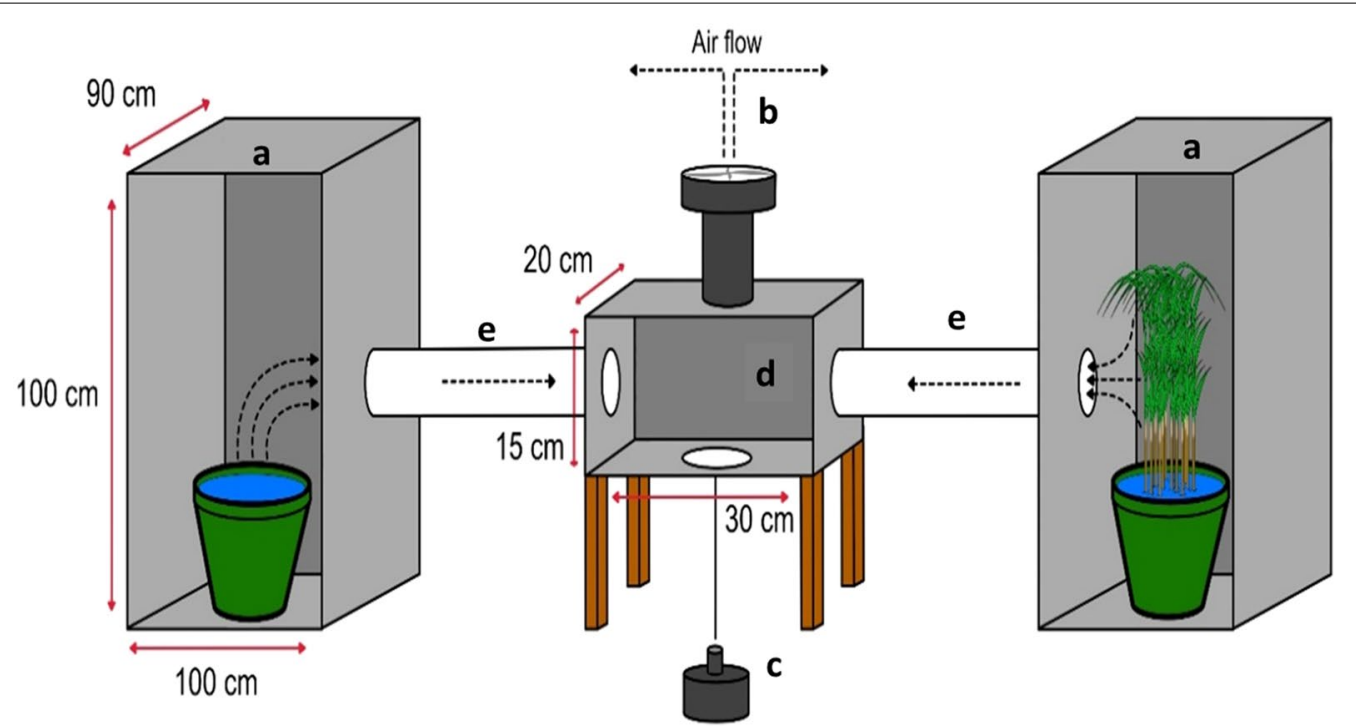

Fig. 1 The olfactometer bioassay experimental setup. The substrates were placed in the two large $(1 \times 0.9 \times 1 \mathrm{~m})$ chambers (a) from which a $12-V$ electric fan (b) drew air to the outside. The fan pipe (c) was fitted on the top side and the mosquito release cup at bottom side of the release chamber (d). The mosquitoes that made a directional choice were trapped in either of the two trapping chambers (e) and data were recorded every morning by removing the fan pipe and the trapping chambers

the following morning at 8:00 by counting the number of mosquitoes trapped in each trapping chamber. The positions of the two test substrates were randomly rotated between chambers and olfactometers so that each substrate spent the same number of nights in each location.

All choice experiments are listed in Table 1. Prior to testing intact plants, the olfactometers were calibrated by evaluating their accuracy in generating valid and reproducible results and gauging the response rate that can be expected under standard test conditions. This was done by providing (1) two equal choices in both chambers (both containing water and both being empty) and (2) by providing two different choices with predictable outcomes (water vs empty; hay-infusion vs water).

After calibration, a series of choice tests were done with intact plant materials (Table 1). Each comparison was replicated over 16 nights using a new batch of mosquitoes and fresh test substrates for every replicate. The replicate was discarded and repeated when mortality was $\geq 20 \%$ in the release/choice chamber or when less than $50 \%$ of the released mosquitoes responded (meaning majority remained in the central release chamber for the night).

\section{Large field-cage experiments with free-flying mosquitoes}

Test treatments that elicited a positive response in olfactometer bioassays were then further evaluated with freeflying gravid An. gambiae s.s. in large field cages $(11.8 \mathrm{~m}$ long $\times 6.8 \mathrm{~m}$ wide $\times 2.4 \mathrm{~m}$ high; Fig. $2 \mathrm{~A}$ ) under ambient environmental conditions to mimic a more natural setting and test for longer-range attraction. The test substrates were placed inside BG-Sentinel traps (Biogents AG, Regensburg, Germany) and these traps were buried in the ground so that only the netting top of the trap and collection funnel containing the fan were visible [51]. A black plastic bucket, $34 \mathrm{~cm}$ high and $30 \mathrm{~cm}$ in diameter, was inserted in each trap to hold the test substrates (Fig. 2B). Two traps with either equal or different test substrates included were set up per field cage (Table 1). The two traps were placed $4 \mathrm{~m}$ apart and $1.4 \mathrm{~m}$ away from the nearest wall. Mosquitoes were released from the opposite side, $9 \mathrm{~m}$ away from the traps (Fig. 2B). The two test substrates were allocated to the location randomly and the position of the two traps were exchanged between the two shorter walls of the cage in consecutive nights. Every experimental night, 200 gravid $A n$. gambiae s.s. were released in the field cage at 18:00. The next morning at 08:00 the traps were collected, and the number of mosquitoes recaptured in the traps' catch bags counted. Every experiment was repeated over 16 nights.

\section{Sample size considerations for bioassays}

The sample size for replication was estimated using the formula developed by Hayes and Bennett [53] for comparing proportions of clustered data. For equal choices, an equal proportion responding to either choice was assumed for the reference $(\mathrm{p} 1=0.5)$. Based on previous work [52], we aimed to be able to detect an increase in attraction by $16 \%(\mathrm{p} 2=0.66)$. Assuming a coefficient of variation $(\mathrm{k})$ of 0.25 based on preliminary nightly 
Table 1 Summary of behavioural bioassays with gravid An. gambiae s.s. in two-port airflow olfactometers and in large field cages in relation to research questions

\begin{tabular}{|c|c|c|c|}
\hline Treatment 1 ('control') & Treatment 2 ('test') & No. of replications & $\begin{array}{l}\text { Total no. of gravid An. gambiae } \\
\text { s.s. re-collected (out of total } \\
\text { released) }\end{array}$ \\
\hline
\end{tabular}

Two-port airflow olfactometer bioassays

Calibration experiments

Do the olfactometer bioassays result in reproducible outcomes? What is the response rate that can be expected from released gravid mosquitoes?

$\begin{array}{llll}\text { Water } & \text { Water } & 16 & 831(1600)^{\mathrm{a}} \\ \text { Empty } & \text { Empty } & 13 & 595(1300) \\ \text { Empty } & \text { Water } & 14 & 707(1400) \\ \text { Water } & \text { Hay infusion } & 12 & 710(1200)\end{array}$

Choice between wet soil vs wet soil + graminoid plant from natural aquatic habitats

Based on previous work on soil infusions [52], is the associated sedge, C. rotundus, attractive to gravid mosquitoes or is attraction based on soil alone?

$\begin{array}{llll}\text { Water } & \text { Water } & 16 & 1060(1600) \\ \text { Soil } & \text { C.rotundus } & 16 & 875(1600)\end{array}$

Choice between water vs water + graminoid plants

Do intact graminoid plants from natural aquatic habitats attract gravid An. gambiae s.s.? Is C. rotundus more attractive than other graminoid plants? Is there a difference in behavioural response to a grass not naturally associated with breeding sites?

$\begin{array}{llrr}\text { Water } & \text { C. rotundus } & 16 & 1245(1600) \\ \text { Water } & \text { C. exaltatus } & 16 & 1204(1600) \\ \text { Water } & \text { P.repens } & 16 & 1194(1600) \\ \text { Water } & \text { C. dactylon } & 16 & 1016(1600) \\ \text { Water } & \text { C. setaceus } & 16 & 1064(1600)\end{array}$

Choice between two graminoid plant species

$\begin{array}{llll}\text { P. repens } & \text { C. rotundus } & 16 & 1224(1600) \\ \text { C. dactylon } & \text { C. rotundus } & 16 & 1179(1600)\end{array}$

Large-cage choice bioassays with free-flying mosquitoes

Do gravid An. gambiae s.s. show similar behavioural response to the plant volatiles at longer-range?

$\begin{array}{llll}\text { Water } & \text { Water } & 16 & 1431(3200) \\ \text { Water } & \text { C.rotundus } & 16 & 2125(3200) \\ \text { Water } & \text { C. exaltatus } & 16 & 2075(3200) \\ \text { Water } & \text { P.repens } & 16 & 1858(3200) \\ \text { Water } & \text { C. dactylon } & 16 & 1988(3200) \\ \text { Water } & \text { C. setaceus } & 16 & 1478(3200) \\ \text { P.repens } & \text { C.rotundus } & 16 & 2234(3200)\end{array}$

${ }^{a}$ Two-equal-choice bioassays using lake water were used as reference experiments. Modified BG-Sentinel mosquito traps were used in large-cage experiments

test runs, and assuming at least 50 responding mosquitoes per night ( $\mathrm{n}$ in each group), 16 replicates would be required for both treatment arms ( 1 1=equal choices; p $2=$ two choices) to detect the effect with $80 \%$ of power at a $5 \%$ significant level.

\section{Bioassay data analysis}

The overall response rate of released mosquitoes was defined as the number of mosquitoes leaving the release chamber in either direction of the olfactometer; hence non-responders remained in the release chamber. Choice experiments using olfactometers and BG-sentinel traps were analysed with generalized linear models with quasi-binomial distributions fitted to cater for overdispersion. The proportions of gravid females responding to the 'test' (as opposed to the 'control') in two-choice experiments with two different choices were compared to the proportion of gravid mosquitoes responding to the 'test' in the experiments where 'test' and 'control' treatments were the same (lake water vs lake water) [54]. The experiment was included as the fixed factor and the 'equal choice' experiment was used as a reference to estimate the odds ratios (OR) and their 95\% confidence intervals $(\mathrm{CI})$. All reported mean proportions and their 95\% confidence intervals (CIs) were estimated based on the model by transforming the log odds (logit) of the 

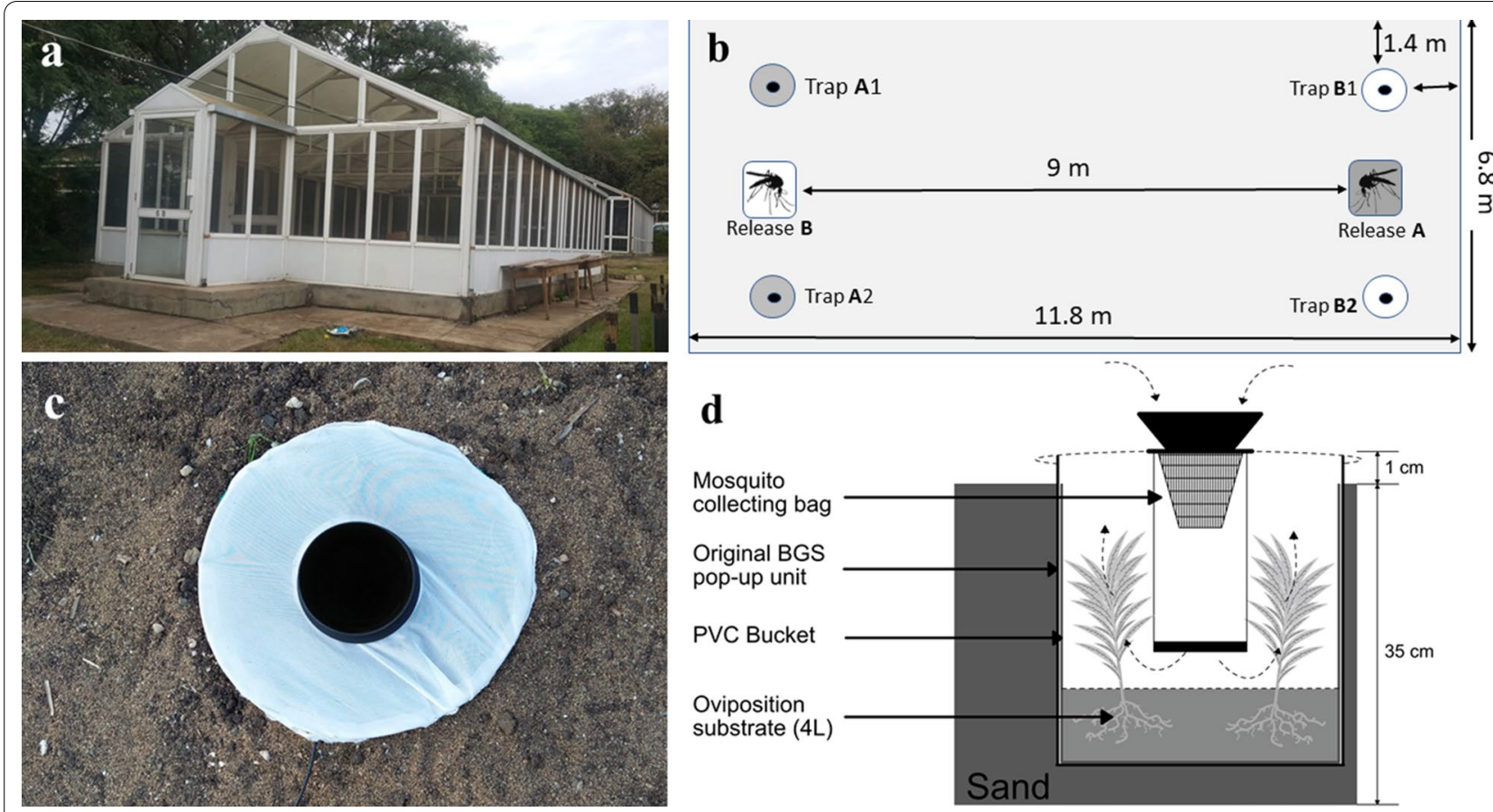

Fig. 2 Overview of experimental set-up in the large field cages (a) with schematic overview of mosquito release points and trap positions (b). The white and blue colours show the trap locations and their respective mosquito release points. Test substrates were provided in modified BG-Sentinel traps buried in the ground (c). The cross-section through the modified BG-Sentinel gravid trap (d) shows the location of the plants and the airflow generated by the trap

outcome to the odds scale and from the odds scale to the probability scale. $\mathrm{R}$ statistical software version 4.0 .3 was used for the analyses [55].

\section{Sampling of headspace from intact plants}

Volatile chemicals released from test plants were trapped from intact live plants using dynamic headspace (DHS) sampling. For this, several non-flowing plants (approximately $350 \mathrm{~g}$ ) were placed with some soil in a bucket with water, similar to the experimental conditions. The sampling was done for $48 \mathrm{~h}$ under ambient conditions in the field cage (Fig. 3). The aerial parts of the intact plants were enclosed into heat-resistant roasting bags (Sainsbury's Supermarkets Ltd, London EC1N 2HT)

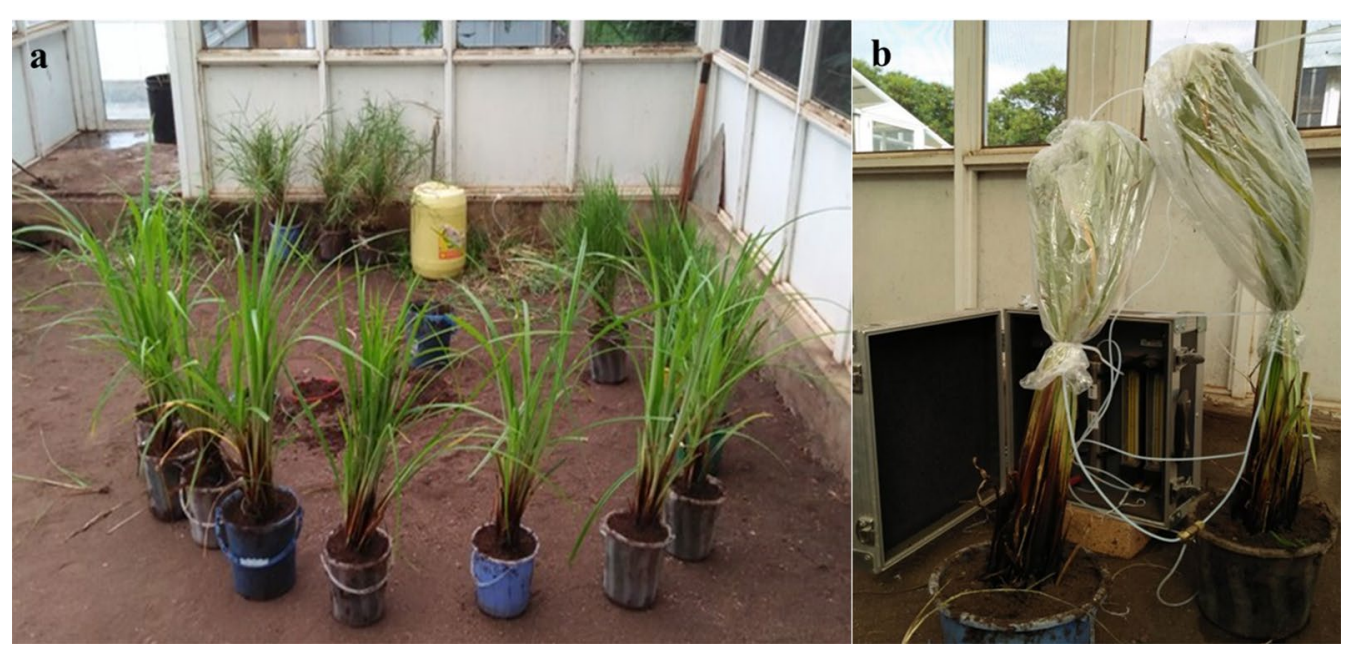

Fig. 3 Plant preparation (a) for dynamic headspace sampling of volatile chemical compounds (b) 
which were kept in an oven at $200{ }^{\circ} \mathrm{C}$ for $2 \mathrm{~h}$ prior to use. Porapak Q (50 mg, 50/80 mesh; Supelco) sorbent material was packed in a glass liner with glass wool on both ends to hold the sorbent in place. The Porapak Q traps were washed using $4 \mathrm{ml}$ of hexane and kept in an oven for $2 \mathrm{~h}$ at $50{ }^{\circ} \mathrm{C}$ before use. Headspace collection was done by pumping $500 \mathrm{ml} / \mathrm{min}$ charcoal-filtered air into the bags through the inlet port and drawing the air out at a rate of $300 \mathrm{ml} / \mathrm{min}$ through the outlet port [56]. Headspace collections were done on two different dates, sampling four replicates of every plant species per date (total 8 headspace samples per plant species). Collections were also done from three replicates of empty cooking bags to account for the background chemicals concurrently for the two dates. After sampling, the traps were sealed with polytetrafluoroethylene (PTFE) tape and kept in a freezer at $-71{ }^{\circ} \mathrm{C}$. The filters were shipped to $\mathrm{KTH}$ Royal Institute of Technology, Stockholm, Sweden, where they were first eluted using $3 \mathrm{ml}$ hexane to decrease the likelihood of chemicals remaining in the trap and then concentrated to $250 \mu \mathrm{l}$ using a desiccator connected to a duo rotary vane pump before chemical analysis.

\section{Chemical analysis based on gas chromatography coupled with mass spectrometry}

The headspace samples were analysed using a Trace 1300 gas-chromatograph (GC) coupled to an ISQ LT massspectrometer (MS; Thermo Fisher, Waltham, MA, USA). For each analysis, $1 \mu \mathrm{l}$ of sample was injected in splitless mode. The temperature program started at $40{ }^{\circ} \mathrm{C}$ and was held for $1.8 \mathrm{~min}$, after which the temperature was ramped to $200{ }^{\circ} \mathrm{C}$ at $20{ }^{\circ} \mathrm{C} / \mathrm{min}$. After reaching $200{ }^{\circ} \mathrm{C}$, the ramp was changed to $50{ }^{\circ} \mathrm{C} / \mathrm{min}$ until the temperature reached $240{ }^{\circ} \mathrm{C}$, at which the temperature was held for $3 \mathrm{~min}$. A $15 \mathrm{~m} \times 0.25 \mathrm{~mm} \times 0.25 \mu \mathrm{m}$ (5\% phenyl)methylpolysiloxane column (Thermo Fisher) was used for all analyses. The carrier gas was helium and had a constant volumetric flow of $1 \mathrm{ml} / \mathrm{min}$ or a linear flow rate of $34 \mathrm{~cm} / \mathrm{s}$. The temperature of the transfer line between the GC and MS was set to $250^{\circ} \mathrm{C}$. The ionization source was an electron impact with ionization energy of $70 \mathrm{eV}$. Heptyl acetate was used as an internal standard to evaluate any instrumental variations for a selection of the replicate analyses. All GC-MS data was handled with Thermo Scientific $^{\text {TM }}$ Xcalibur $^{\text {TM }}$ software. Results from the mass spectrometry were submitted to the National Institute of Standards and Technology (NIST) MS Search 2.0 program for the NIST/US Environmental Protection Agency (EPA)/National Institutes of Health (NIH) Mass Spectral Library version $2.0 \mathrm{~g}$. The VOCs of the plants were identified using mass spectrometry (MS), retention time index (RI) and external standards (Ext Std). For each plant type, a minimum of two replicates from two different rounds were analysed to identify consistent compounds. For each plant type, one sample was also analysed three times to evaluate the variations in the same sample due to any possible instrumental drifts. For the calculation of the linear retention time index, the 49452-U C7-C40 alkane standard (Supelco, Bellefonte, PA, USA) was used as a reference. The cannabis terpene mix CRM 40755 (Sigma Aldrich, St. Louis, MO, USA) was used as external standards. The mix contained the following 20 terpenes $\alpha$-pinene, $\beta$-pinene, camphene, 3 -carene, $\alpha$-terpinene, $\mathrm{R}$-(+)-limonene, $\gamma$-terpinene, $\mathrm{L}-(-)$-fenchone, fenchol, (1R)-(+)-camphor, isoborneol, menthol, citronellol, $(+)$-pulegone, geranyl acetate, $\alpha$-cedrene, $\alpha$-humulene, nerolidol, $(+)$-cedrol and $\alpha-(-)$-bisabolol. This standard was complemented with the $\beta$-caryophyllene standard 22075 (Sigma-Aldrich) and the (-)-caryophyllene oxide 91034 (Sigma-Aldrich), to confirm the identified compounds. The area percentage was determined as the quotient between the area of compound peak as the numerator and the sum of all peaks detected in the corresponding chromatogram as the denominator. The mean area percentage was then calculated from all the DHS samples analysed and reported in the results. The peak areas were determined using the ICIS peak detection method in Xcalibur ${ }^{\mathrm{TM}}$ software.

\section{Results}

\section{Two-port airflow olfactometer bioassays}

The preliminary calibration experiments helped gauge the performance of the bioassay design and apparatus. During the majority of the preliminary experimental runs, around $50 \%$ of the released mosquitoes responded, whilst the others remained in the release chamber. This proportion could not be increased even when the experimental set up was modified. Hence, for all following experiments, it was defined that for a viable outcome the response rate must be $50 \%$ or above. When two equal choices of water were provided in the chambers, the released gravid mosquitoes distributed equally between the two chambers as expected (Table 2). When both chambers were empty, mosquitoes still responded, likely flying upwind in search of cues, and again distributed equally between the two chambers. The response rate, however, was overall slightly lower (46\%) than when water was provided. When a choice between water in one chamber and no substrate in the other chamber was provided, $>80 \%$ of the responding females chose water. This confirmed that water vapour acts as an attractant for gravid mosquitoes. Moreover, it was confirmed that fermented 3-day-old hay infusion repels gravid An. gambiae s.s. Out of all responding females, $>70 \%$ oriented away from the infusion and towards the chamber with water. 
Table 2 Preliminary olfactometer calibration experiments with gravid An. gambiae s.S.

\begin{tabular}{|c|c|c|c|c|}
\hline Experiment & 'Control'substrate & 'Test'substrate & $\begin{array}{l}\text { Percent }(\%) \text { response of all } \\
\text { released }(95 \% \mathrm{Cl})\end{array}$ & $\begin{array}{l}\text { Percent (\%) attracted to } \\
\text { 'test' of all responders } \\
(95 \% \mathrm{Cl})\end{array}$ \\
\hline 1 & Empty & Empty & $46(38-53)$ & $52(46-58)$ \\
\hline 2 & Empty & Lake water & $51(43-58)$ & $80(75-84)$ \\
\hline 3 & Lake water & Lake water & $52(45-59)$ & $49(44-54)$ \\
\hline 4 & Lake water & Infusion & $59(52-67)$ & $29(24-35)$ \\
\hline
\end{tabular}

$\mathrm{Cl}$ confidence interval

After confirming the consistent performance of the bioassay, three sets of experiments were implemented. Equal choice experiment where the mosquitoes were provided with lake water in both chambers randomly allocated as 'test' and 'control', were set in parallel for all three sets of experiments. As expected, these reference test resulted in an approximate 1:1 distribution of gravid females (Fig. 4). Any preference for a specific test substrate in choice tests was expected to lead to a significant deviation from this balanced distribution.

Previous work [17] implicated soil from the C. rotundus collection site as attractive oviposition substrate for gravid An. gambiae s.s. Consequently, in a first step, we evaluated whether wet soil from the location might be equally or more attractive in olfactometer bioassays than the live $C$. rotundus plants in the same wet soil. However, the odds of a gravid female selecting the test chamber with the plants was nearly threefold higher than in the reference experiment (OR 2.93; Fig. 4). Removing the soil completely from the bioassay increased the odds further when compared to the reference (OR 4.95). Consequently, another four graminoid plants were tested and all of them released volatile chemicals attractive to gravid An. gambiae s.s. females (Fig. 4) in the airflow olfactometer. The odds of finding a gravid female in the test chamber with the plants were 2.4-5 times higher than in the reference experiment, with the most profound effect induced by $C$. rotundus. Even the drought-resistant $C$. setaceus, not naturally associated with mosquito breeding sites, elicited a significant positive orientation towards the plants' odours (OR 2.41). The attractiveness of $C$. rotundus was further investigated when presented in choice tests with the Poaceae species, P. repens and C. dactylon. Chemical

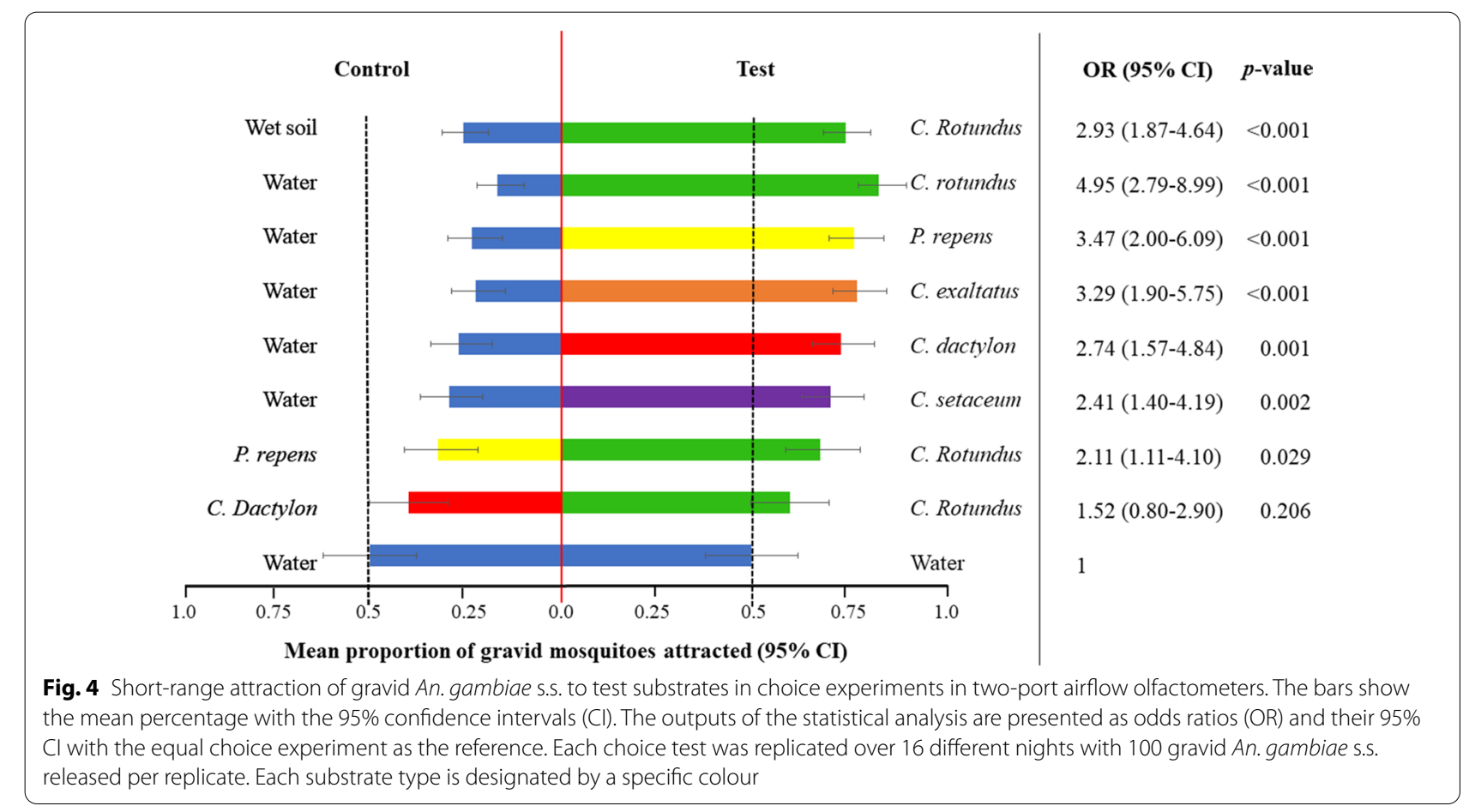


volatiles released from C. rotundus were preferred over the other grasses, though the effect size was moderate (Fig. 4).

\section{Large field-cage experiments with free-flying mosquitoes}

Bioassays with free-flying gravid mosquitoes confirmed olfactometer results with higher proportions of the released gravid females trapped with BG-Sentinel traps containing live plants than with traps that contained water only (Fig. 5). The odds of a female being captured in the test traps in the two-choice experiments were 1.52.5 times higher than in the reference experiment. Differences in the effect size of attraction between the plant species were not very pronounced under these more natural, long-range conditions, though C. rotundus volatiles did slightly outcompete volatiles from $P$. repens in a similar way as in the olfactometer bioassays (Fig. 5).

\section{Volatile organic compounds identified from the graminoid test plants}

Chemical analyses were done for 21 headspace samples: C. rotundus $(n=5), C$. dactylon $(n=4), C$. exaltatus $(n=4), P$. repens $(n=4)$ and C. setaceus $(n=4)$. A total of 43 VOCs were detected with mass spectrometry (Table 3). A complete list of detected VOCs from each analysis of the different samples of the graminoid plants is shown in the Additional file 1: Table S1. The qualitative analysis shows that almost half of the detected compounds were sesquiterpenes. The second most common chemical class was monoterpenes, followed by a number of cyclic and straight compounds such as cyclic ketones, aliphatic esters and aromatic compounds. Table 3 shows compounds that have been detected in any one headspace sample of a plant species. There was a slight overlap in the profiles of monoterpenes and sesquiterpenes which were identified from different plant species (Table 3). Compounds such as limonene, $\beta$-caryophyllene, $\beta$-elemene, 1,1-dimethyl-3-methylene-2-vinylcyclohexane and $\alpha$-guaiene were present in the headspace of at least three out of four graminoid plants. Unlike the other graminoid species, $C$. setaceus, contained more aromatic compounds and had less overlap with the other species in its chemical profile. Overall, roughly $10 \%$ of the VOCs were detected in the headspace of four of the five plants, while around $65 \%$ of the VOCs were detected from only a single species. This shows the diversity of the headspace in the chemical environment of the malaria vector.

\section{Discussion}

Our study confirms and expands the evidence that odour cues released from graminoid plants play a role in the orientation of gravid An. gambiae s.s. females. Volatiles released from these plants add significant attraction to water vapour alone. Generally, all graminoid plant species tested, including the dry-land ornamental grass $C$. setaceus, usually not associated with mosquito breeding sites, significantly attracted gravid females, and behavioural differences in response to different test plants were

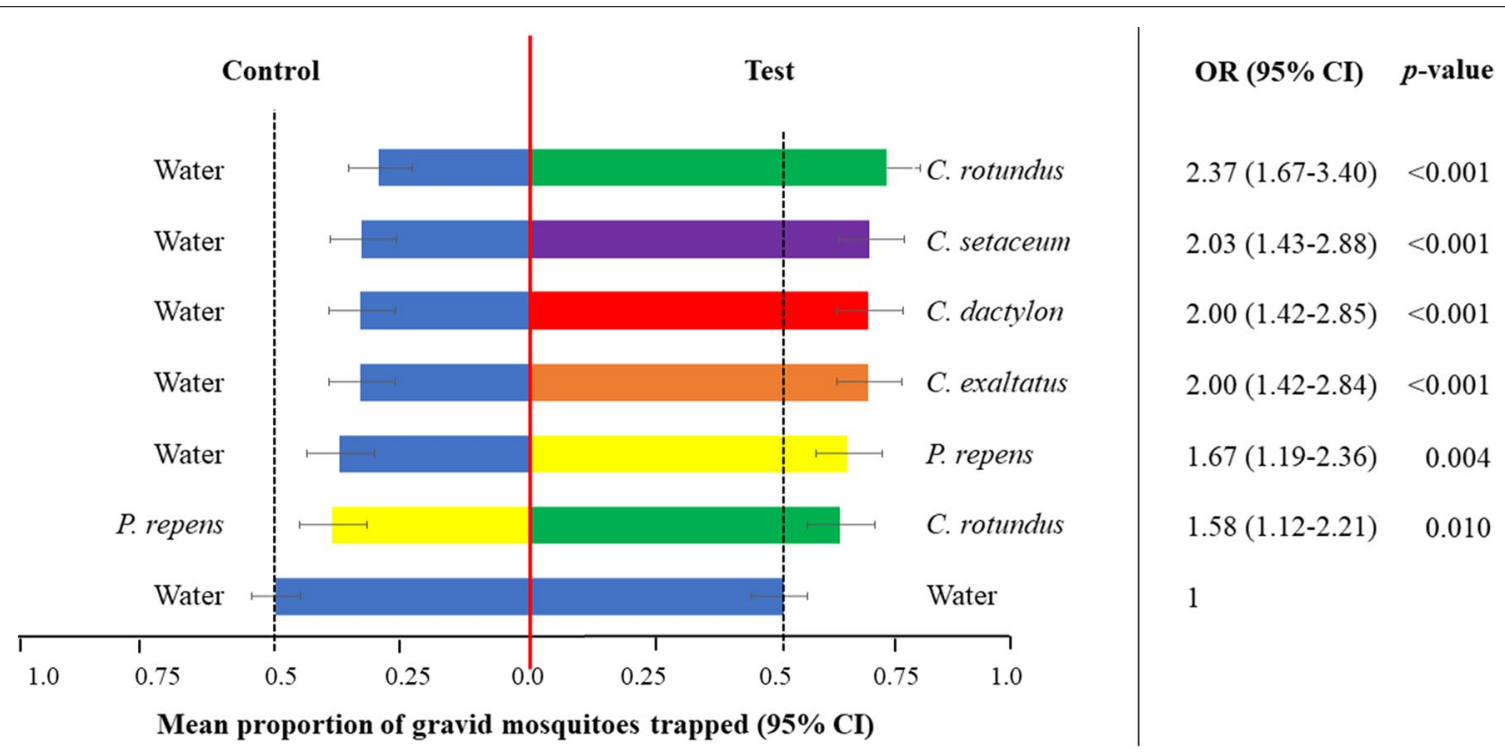

Fig. 5 Long-range attraction of gravid An. gambiae s.s. to test substrates in choice experiments in large field cages. The bars show the mean percentage with the $95 \%$ confidence intervals $(\mathrm{Cl})$. The outputs of the statistical analysis are presented as odds ratios (OR) and their $95 \% \mathrm{Cl}$ with the equal choice experiment as the reference. Each choice test was replicated over 16 different nights with 200 gravid An. gambiae s.s. released per replicate. Each substrate type is designated by a specific colour 
Table 3 Volatile profile of dynamic headspace sampling of aerial parts from C. rotundus (CR), C. exaltatus (CE), C. dactylon (CD), P. repens (PR) and C. setaceus (CS)

\begin{tabular}{|c|c|c|c|c|c|c|c|c|c|}
\hline \multirow[t]{2}{*}{ Volatile compound } & \multicolumn{6}{|c|}{ Area (\%) composition \pm SE } & \multirow[t]{2}{*}{ EAD Spec. } & \multirow[t]{2}{*}{ Physiol. stage } & \multirow[t]{2}{*}{ Ref. } \\
\hline & $\mathrm{Rl}$ & $C R$ & CE & $C D$ & $P R$ & CS & & & \\
\hline \multicolumn{10}{|l|}{ Primary alcohol } \\
\hline 2-Ethyl-1-hexanol & 1039 & - & - & $0.41 \pm 0.322$ & - & - & - & - & \\
\hline \multicolumn{10}{|l|}{ Aliphatic ketone } \\
\hline Sulcatone & 992 & - & - & $0.038 a$ & - & - & $\mathrm{Aa}$ & G & [22] \\
\hline \multicolumn{10}{|l|}{ Aliphatic ester } \\
\hline 4-Hexen-1-ol acetate & 1012 & - & - & $3.338 \pm 1.867$ & - & - & - & - & \\
\hline \multicolumn{10}{|l|}{ Cycloalkane } \\
\hline $\begin{array}{l}\text { 1-Isobutyl-1-cyclohex- } \\
\text { ene }\end{array}$ & 955 & - & $0.139 a$ & - & - & - & - & - & \\
\hline \multicolumn{10}{|l|}{ Cyclic ketone } \\
\hline $\begin{array}{r}\text { Cyclohexanone, } \\
\text { 2,2,6-trimethyl }\end{array}$ & 1043 & - & - & $0.102 \pm 0.041$ & - & - & - & - & \\
\hline Isophorone & 1069 & - & - & $0.111 \pm 0.088$ & - & - & - & - & \\
\hline \multicolumn{10}{|l|}{ Aromatic } \\
\hline 1,4-Diethylbenzene & 1056 & - & - & - & - & $1.433 \pm 0.676$ & - & - & \\
\hline Cymene & 1062 & - & - & - & - & $0.351 \pm 0.368$ & $\mathrm{Aa}, \mathrm{Ag}$ & G & {$[22,44,57]$} \\
\hline $\begin{array}{l}\text { 2,4-Dimethyl-acetophe- } \\
\text { none }\end{array}$ & 1277 & $0.392 \pm 0.324$ & - & - & - & $0.514 \pm 0.385$ & - & - & \\
\hline $\begin{array}{l}\beta \text {-Hydroxyethyl phenyl } \\
\text { ether }\end{array}$ & 1298 & - & - & - & - & $0.089 a$ & - & - & \\
\hline $\begin{array}{l}\text { 1H-indene, 1-ethyl- } \\
\text { idene }\end{array}$ & 1313 & - & - & - & - & $0.004 a$ & - & - & \\
\hline \multicolumn{10}{|l|}{ Alkyne } \\
\hline 4,6-Decadiyne & 1063 & - & - & - & - & $0.475 \pm 0.043$ & - & - & \\
\hline \multicolumn{10}{|l|}{ Aromatic monoterpene } \\
\hline Cumic alcohol & 1271 & $0.418 \pm 0.358$ & - & - & - & $0.347 \pm 0.308$ & - & - & \\
\hline \multicolumn{10}{|l|}{ Monoterpene } \\
\hline a-Pinene & 942 & - & - & $0.035 \pm 0.026$ & - & - & $\mathrm{Aa}$ & G & {$[22,44]$} \\
\hline$\beta$-Pinene & 980 & $0.632 \pm 0.287$ & $0.021 a$ & $0.042 \pm 0.035$ & - & - & $\mathrm{Aa}, \mathrm{Ag}$ & $\mathrm{G}, \mathrm{U}$ & {$[22,57,58]$} \\
\hline Myrcene & 994 & $0.452 \pm 0.135$ & - & - & - & - & $\mathrm{Ag}$ & U & {$[59,60]$} \\
\hline Limonene & 1035 & $2.805 \pm 1.127$ & $1.043 \pm 0.31$ & $0.088 \pm 0.069$ & $0.037 \pm 0.018$ & - & $\mathrm{Aa}, \mathrm{Ag}$ & $\mathrm{G}, \mathrm{U}$ & {$[22,43,57,58]$} \\
\hline Eucalyptol & 1039 & - & - & - & $0.877 \pm 0.27$ & - & - & - & \\
\hline 4-Thujanol & 1078 & - & - & $0.076 \pm 0.067$ & - & - & - & - & \\
\hline $\begin{array}{l}\text { 1,1-Dimethyl-3-methyl- } \\
\text { ene-2-vinylcyclohex- } \\
\text { ane }\end{array}$ & 1121 & $1.554 \pm 0.672$ & $0.78 \pm 0.591$ & $0.188 a$ & - & $0.072 a$ & - & - & \\
\hline Camphor & 1158 & - & - & $0.028 \pm 0.03$ & - & - & - & - & \\
\hline$\beta$-Cyclocitral & 1234 & - & - & $0.118 \pm 0.069$ & $0.025 \pm 0.016$ & - & - & - & \\
\hline \multicolumn{10}{|l|}{ Sesquiterpene } \\
\hline Unidentified $\mathrm{M}=[204]^{*}$ & 1356 & - & - & $0.135 \pm 0.06$ & - & - & - & - & \\
\hline Ylangene & 1362 & - & - & - & $0.115 \pm 0.134$ & - & - & - & \\
\hline Cyclosativene & 1383 & - & - & $0.194 \pm 0.081$ & - & - & - & - & \\
\hline Copaene & 1389 & $0.569 \pm 0.372$ & - & $0.044 \pm 0.025$ & - & - & - & - & \\
\hline Y-Elemene & 1396 & $0.093 \pm 0.028$ & - & - & - & - & $\mathrm{Ag}$ & U & {$[61]$} \\
\hline$\beta$-Elemene & 1404 & $3.64 \pm 1.038$ & $0.951 a$ & $0.069 \pm 0.059$ & $0.54 \pm 0.19$ & - & & & \\
\hline Cyperene & 1418 & $0.584 \pm 0.111$ & $0.916 \pm 0.514$ & - & - & - & - & - & \\
\hline a-Gurjunene & 1419 & - & - & $0.134 \pm 0.113$ & - & - & - & - & \\
\hline Cedrene & 1436 & - & $0.101 \pm 0.073$ & - & - & - & $\mathrm{Ag}$ & U & [59] \\
\hline$\beta$-Caryophyllene & 1438 & $3.517 \pm 1.668$ & $1.953 \pm 0.641$ & $0.141 \pm 0.031$ & - & - & $\mathrm{Aa}, \mathrm{Ag}$ & $\mathrm{G}, \mathrm{U}$ & {$[22,57,59,60]$} \\
\hline
\end{tabular}


Table 3 (continued)

\begin{tabular}{|c|c|c|c|c|c|c|c|c|c|}
\hline \multirow[t]{2}{*}{ Volatile compound } & \multicolumn{6}{|c|}{ Area (\%) composition \pm SE } & \multirow[t]{2}{*}{ EAD Spec. } & \multirow[t]{2}{*}{ Physiol. stage } & \multirow[t]{2}{*}{ Ref. } \\
\hline & $\mathrm{Rl}$ & $C R$ & CE & $C D$ & $P R$ & CS & & & \\
\hline a-Bergamotene & 1448 & - & - & $0.096 \pm 0.082$ & - & - & - & - & \\
\hline$\beta$-lonone & 1453 & - & - & $0.115 \pm 0.009$ & - & - & - & - & \\
\hline Humulene & 1473 & $2.376 \pm 0.96$ & $0.429 \pm 0.279$ & - & - & - & $\mathrm{Ag}$ & U & {$[59,60]$} \\
\hline 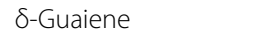 & 1482 & - & - & $1.036 \pm 1.696$ & - & - & - & - & \\
\hline Germacrene D & 1500 & - & $0.726 \pm 0.471$ & $0.126 \pm 0.084$ & - & - & - & - & \\
\hline a-Guaiene & 1502 & $0.518 \pm 0.2$ & $0.132 \pm 0.265$ & $0.145 \pm 0.163$ & $0.072 \mathrm{a}$ & - & - & - & \\
\hline a-Muurolene & 1516 & - & $0.195 \pm 0.109$ & $0.099 \pm 0.038$ & - & - & - & - & \\
\hline$\delta$-Cadinene & 1535 & - & $0.796 \pm 0.094$ & - & - & - & $\mathrm{Ag}$ & $U$ & {$[59]$} \\
\hline Caryophyllene oxide & 1609 & $0.281 \pm 0.165$ & - & - & - & - & - & - & \\
\hline Humulene epoxide II & 1639 & $0.591 \pm 0.887$ & - & - & - & - & - & - & \\
\hline $\begin{array}{l}\text { Hexahydrofarnesyl } \\
\text { acetone }\end{array}$ & 1853 & - & - & $1.463 \pm 0.379$ & - & - & - & - & \\
\hline
\end{tabular}

$R /$ retention index calculated on a $15 \mathrm{~m} \times 0.25 \mathrm{~mm} \times 0.25 \mu \mathrm{m}\left(5 \%\right.$ phenyl)-methylpolysiloxane column. SE standard error. $M=[204]^{*}$ compound with the following 10 strongest MS peaks: 91(100), 105(98), 71(86), 133(77), 107(69), 93(62), 55(55), 77(52), 79(49), 69(47)

$a$ No standard error is calculated, as the compound was only detected in one of the headspace samples. Aa Anopheles arabiensis; Ag Anopheles gambiae s.s. EAD electroantennogram detection published for Anopheles species. G EAD done for gravid females, U EAD done for unfed females

not very pronounced especially under the more natural, longer-range trapping conditions.

Whilst the behavioural response of gravid An. gambiae s.s. mosquitoes appeared to be slightly stronger in reaction to the sedge, $C$. rotundus, than to most other test plants, we were not able to exactly establish any unique differences in the chemical profiles that might explain this. This is likely, in part, due to the chemical sampling method. To the best of our knowledge, our bioassays are the first to use live plants rather than eluted headspace extracts for testing for attractiveness to gravid malaria vectors. Our aim was to test the behavioural response of gravid females to plant volatiles under as natural conditions as possible. Plant volatiles react differentially with atmospheric oxidants, such as ozone, resulting in odour plumes that not only include the plant-emitted volatile chemicals but also gradually include a blend of degradation products [36], which might not be picked up during DHS sampling with filtered air. We had opted for headspace sampling, since it is a non-destructive method for sampling the volatile profile emitted by plants which might consequently be detected by insects [62]. The pooled analyses of our headspace samples suggest that there are variations between the chemical profiles of the different plant species. It is unclear, however, whether these differences would be consistent over time and under different environmental conditions, and whether they are responsible for the variations observed in attracting gravid females in the bioassays. Our GC results have been highly variable between replicate plant samples of the same species (Additional file 1: Table S1) with some samples not resulting in any detectable compounds. This is not unexpected, given that we have taken only a 'snapshot' of volatiles released at a particular time point and without carefully standardizing plant age and development. Some volatiles may be emitted in quantities below technical detectability, yet these might be functionally relevant for insect attraction [36]. Volatile organic chemicals emissions and concentrations are also affected by light, temperature, nutritional and soil-moisture conditions, and even by species composition of the neighbouring plant community [63-69]. Abiotic stresses, including stress induced by the air sampling itself when plant material is enclosed in plastic bags will also affect the volatile profile. Going forward, it will be desirable to sample under natural, yet varying environmental conditions and to compare results across different sampling strategies [62] for a better understanding of the composition and concentration of compounds in the headspace of plants that might affect natural mosquito behaviour.

In our study, and across published work, we see very little variation in the strengths of the behavioural response of gravid mosquitoes to varied graminoid plant species, despite the fact that volatile profiles appear variable. The behavioural response of gravid An. gambiae s.s. induced by the wild graminoid plants in our bioassays was in the same ranges as those reported previously for $A n$. arabiensis and $A n$. coluzzi in response to low release rates of headspace extracts from rice plants [22] and from the tropical African wetland grasses (Poaceae) Echinochloa pyramidalis, E. stagnina and Typha latifolia [42]. It was also in a similar range as observed for the attraction of unfed females to plant-based volatiles [58, 60, 70]. A limitation of our study was our inability to access equipment 
for electroantennography to determine exactly which volatile chemicals released from the test plants were detected by the gravid female's antenna. However, when comparing the volatile chemicals identified in our study with those published for rice plants and pollen from sugar cane and maize in the context of oviposition [22, 43, 44], as well as with those published for a range of plants preferentially visited by malaria vectors for sugar feeding [32, 58-60], it becomes apparent that there is significant overlap in the chemical compositions. Compounds reported here, such as limonene, $\alpha$ - and $\beta$-pinene, $\mathrm{p}$-cymene, sulcatone, humulene, cedrene, $\beta$-myrcene, and $\beta$-caryophyllene, have previously been reported to elicit electrophysiological responses in gravid and unfed female Anopheles [22, $43,44,57-60]$, and many of them have been formulated into synthetic blends and shown to be attractive to unfed and gravid Anopheles under highly standardized experimental conditions $[22,43,58,71]$. These compounds are among the most common VOCs emitted from plants [72] since they are synthesized through biosynthetic pathways common in most plants [39, 73, 74].

In our study, three volatile chemicals, namely 1,1-dimethyl-3-methylene-2-vinylcyclohexane, $\alpha$-guaiene and $\beta$-elemene, have not been tested previously, yet were detected frequently in four out of the five test plants. It might be useful to explore their potential to manipulate odour-orientation of Anopheles mosquitoes in followup studies, since they have been implicated as semiochemicals for other insect species [75-79]. For example, 1,1-dimethyl-3-methylene-2-vinylcyclohexane was attractive to the beech leaf-mining weevil [76], guaiene has been suggested to play a role in the attraction of the litchi stem-end borer [80] and $\beta$-elemene has been implied to contribute to attraction of the gravid tobacco moths [77] and the white-spotted longhorn beetle [78].

Myrcene, $\gamma$-elemene, humulene epoxide II and hexahydrofarnesyl acetone were specific to headspace samples of C. rotundus in our analysis. This does not, however, necessarily imply that these compounds contributed to the attractiveness in our bioassays. Information on these compounds as info-chemicals for insects and specifically mosquitoes is scant and none of them have been tested with gravid malaria vectors. Both unfed Anopheles and unfed Aedes mosquitoes showed electrophysiological activity to $\beta$-myrcene in previous studies $[60,70]$. It was observed that myrcene elicits an avoidance behaviour in unfed $A n$. gambiae searching for sugar [60] or blood meals [81]. $\gamma$-Elemene was identified from plant headspace and found to be electrophysiologically active for unfed An. gambiae, but behavioural implications were not studied [61].

Gravid malaria vectors navigate a complex chemical environment in search of oviposition sites. It is plausible to assume that volatile chemical cues emanating from aquatic habitats and their surroundings are only used at relatively short-range, with visual cues and air movements guiding the gravid females' flight towards a water body [1, 82]. Visual cues will include near-infrared radiation from slowly released heat from water bodies in the evening [83], polarized light from water surfaces [84], as well as ultraviolet light [85], all of which present strong long-range cues likely used by gravid mosquitoes to evaluate the location and quality of potential oviposition sites [2]. In this context, therefore, it remains unclear whether attractive, yet common, plant-based semiochemicals in odour-baited traps will be able to compete in an attract-and-kill approach, with the complex interaction of cues provided by natural aquatic habitats. To date over 100 semiochemicals have been identified for mosquitoes of all physiological stages, yet synthetic odour-baited traps hardly play any role in contemporary surveillance and control of malaria vector mosquitoes [4]. Synthetic odour-baits mimicking human body odour have been shown to perform poorly in attracting hostseeking Anopheles mosquitoes when present in close proximity to natural human blood hosts [86] and field evaluations of the oviposition attractant cedrol, showed that visual cues provided by an open water surface were essential in combination with the chemical cue to attract wild oviposition-site searching females [17]. In order to develop vector control interventions that manipulate the odour-orientation of malaria vectors in their natural environment, less emphasis might be placed in future on detecting more semiochemicals but more emphasis on how to formulate and present these chemicals in combination with other essential cues used by mosquitoes, to improve the efficacy of such interventions [4].

\section{Conclusions}

Our results suggest that plant volatiles provide a more general cue for gravid malaria vectors rather than vectors being highly adapted and evolved in context to specific plant species and environments. All the graminoid test plants were very common, occurring in high abundance in grasslands and wetlands in sub-Saharan Africa and beyond [87-91]. Our results also challenge a previous suggestion [42] that volatile chemicals released from the grass family Poaceae are in general more attractive to gravid Anopheles mosquitoes than those released from the sedge family Cyperaceae. The variations in chemical profiles and behavioural responses have been shown to be subtle across all studies. Productive breeding sites have been associated with species from both plant families in a number of field surveys $[24,26,29,40]$. In nature, plant-based chemical cues interact with many other biotic and abiotic environmental cues to help gravid malaria vectors to orient and select suitable egg-laying 
sites, including non-plant-based chemicals [17, 18, 41, 92, 93], light and reflection [82], contrast [94], structure including plant height [29], conspecific immature stages $[16,95,96]$, and other macroinvertebrates $[14,97]$. These complex interactions will need to be taken into consideration when designing 'attract-and-kill' strategies targeting gravid vectors with odour-baited traps.

\section{Abbreviations}

GC-MS: Gas chromatography-mass spectrometry; icipe-TOC: International Centre of Insect Physiology and Ecology-Thomas Odhiambo Campus; PVC: Polyvinyl chloride; LLIN: Long-lasting insecticide nets; IRS: Indoor residual sprays; VOC: Volatile organic compound; WHO: World Health Organization.

\section{Supplementary Information}

The online version contains supplementary material available at https://doi. org/10.1186/s13071-021-04939-4.

Additional file 1. A complete list of detected volatile organic compounds from each analysis of the different samples of Cyperus rotundus (CR), Cyperus exaltatus (CE), Cynodon dactylon (CD), Panicum repens (PR) and Cenchrus setaceum (CS).

\section{Acknowledgements}

We acknowledge the technical support of Paul Ouma. We thank David Alila and Elisha Obudho for rearing and providing the mosquitoes used in the bioassays. We are grateful to Mike Okal, David Tchouassi and Jenny Lindh for their scientific guidance and to Ibrahim Kiche for the administrative assistance.

\section{Authors' contributions}

UF and $\AA$ E conceived the initial idea for this research and secured the funding. UF and GB developed the experimental designs and standard operating procedures for the behavioural ecology experiments with support from TB. GB and RT implemented the behavioural ecology experiments and curated the data. GB analysed the data from the experiments. LS and ÅE developed the protocols and implemented the chemical analysis of plant headspace samples. GB and UF drafted the manuscript with support from LS. PO provided supervision and academic guidance. All authors contributed to the interpretation of data and the final draft. All authors read and approved the final manuscript.

\section{Funding}

The authors gratefully acknowledge the financial support from the International Centre of Insect Physiology and Ecology, Kenya, facilitated by its core donors the UK's Foreign, Commonwealth \& Development Office (FCDO); the Swedish International Development Cooperation Agency (Sida); the Swiss Agency for Development and Cooperation (SDC); the Federal Democratic Republic of Ethiopia; and the Government of the Republic of Kenya. We further acknowledge support from the Swedish Research Council (Grant number-VR 2015-03159) and the Carl Trygger Foundation for Scientific Research (Grant number-CTS18:97). GB was supported by a German Academic Exchange Service (DAAD) In-Region Postgraduate Scholarship. The views expressed herein do not necessarily reflect the official opinion of the donors. The funders had no role in the study design, data collection and analysis, preparation of the manuscript or decision to publish.

\section{Availability of data and materials}

The datasets for the plant headspace chemical analysis can be found at Figshare https://doi.org/10.6084/m9.figshare.14790162. The primary datasets generated from the bioassays and analysed are available from the corresponding authors on reasonable request.

\section{Declarations}

\section{Ethics approval and consent to participate}

Approval for this study was obtained from the Kenya Medical Research Institute's Ethical Review Committee (Protocol no. 593) and the National Commission for Science, Technology and Innovation, Kenya (License No: NACOSTI/P/20/6222).

\section{Consent for publication}

Not applicable.

\section{Competing interests}

The authors declare that they have no competing interests.

\section{Author details}

${ }^{1}$ International Centre of Insect Physiology and Ecology, P.O. Box 30772-00100, Nairobi, Kenya. ${ }^{2}$ School of Physical and Biological Sciences, Department of Zoology, Maseno University, Maseno, Kenya. ${ }^{3}$ Ethiopian Public Health Institute, P. O. Box 1242, Addis Ababa, Ethiopia. ${ }^{4}$ Analytical Chemistry, Div. of Applied Physical Chemistry, Dept. of Chemistry, KTH Royal Institute of Technology, Stockholm, Sweden.

Received: 21 June 2021 Accepted: 9 August 2021

Published online: 27 October 2021

\section{References}

1. Bentley MD, Day JF. Chemical ecology and behavioral aspects of mosquito oviposition. Ann Rev Entomol. 1989;34:401-21.

2. Day J. Mosquito oviposition behavior and vector control. Insects. 2016;7:65.

3. Ferguson HM, Dornhaus A, Beeche A, Borgemeister C, Gottlieb M, Mulla MS, et al. Ecology: a prerequisite for malaria elimination and eradication. PLoS Med. 2010;7:e1000303.

4. Wooding M, Naudé Y, Rohwer E, Bouwer M. Controlling mosquitoes with semiochemicals: a review. Parasit Vectors. 2020;13:80.

5. Pates $\mathrm{H}$, Curtis C. Mosquito behavior and vector control. Annu Rev Entomol. 2005;50:53-70

6. Russell TL, Govella NJ, Azizi S, Drakeley CJ, Kachur SP, Killeen GF. Increased proportions of outdoor feeding among residual malaria vector populations following increased use of insecticide-treated nets in rural Tanzania. Malar J. 2011;10:80.

7. Reddy MR, Overgaard HJ, Abaga S, Reddy VP, Caccone A, Kiszewski AE, et al. Outdoor host seeking behaviour of Anopheles gambiae mosquitoes following initiation of malaria vector control on Bioko Island, Equatorial Guinea. Malar J. 2011:10:184.

8. Russell TL, Beebe NW, Cooper RD, Lobo NF, Burkot TR. Successful malaria elimination strategies require interventions that target changing vector behaviours. Malar J. 2013;12:56.

9. Govella NJ, Chaki PP, Killeen GF. Entomological surveillance of behavioura resilience and resistance in residual malaria vector populations. Malar J. 2013;12:124.

10. Clements AN. The biology of mosquitoes, volume 1: development, nutrition and reproduction. Wallingford: CABI Publishing; 1992.

11. Pencer MAS, Laustein LEONB, Spencer M, et al. Oviposition habitat selection by mosquitoes (Culiseta longiareolata) and consequences for population size. Ecology. 2002;83:669-79.

12. Clements AN. The biology of mosquitoes, volume 2 : sensory reception and behaviour. Wallingford: CABI Publishing; 1999.

13. Mwingira V, Mboera LEG, Dicke M, Takken W. Exploiting the chemical ecology of mosquito oviposition behavior in mosquito surveillance and control: a review. J Vector Ecol. 2020;45:155-79.

14. Munga S, Minakawa N, Zhou G, Barrack O-OJ, Githeko AK, Yan G. Effects of larval competitors and predators on oviposition site selection of Anopheles gambiae sensu stricto. J Med Entomol. 2006;43:221-4.

15. Blaustein L, Kiflawi M, Eitam A, Mangel M, Cohen JE. Oviposition habitat selection in response to risk of predation in temporary pools : mode of detection and consistency across experimental venue. Behav Ecol. 2004; 138:300-5. 
16. Schoelitsz B, Mwingira V, Mboera LEG, Beijleveld H, Koenraadt CJM, Spitzen J, et al. Chemical mediation of oviposition by Anopheles mosquitoes: a push-pull system driven by volatiles associated with larval stages. J Chem Ecol. 2020;46:397-409.

17. Lindh JM, Okal MN, Herrera-Varela M, Borg-Karlson A-K, Torto B, Lindsay SW, et al. Discovery of an oviposition attractant for gravid malaria vectors of the Anopheles gambiae species complex. Malar J. 2015;14:119.

18. Afify A, Galizia CG. Chemosensory cues for mosquito oviposition site selection. J Med Entomol. 2015:52:120-30.

19. Dormont L, Mulatier M, Carrasco D, Cohuet A. Mosquito attractants. J Chem Ecol. 2021;47:351-93.

20. Okal MN, Francis B, Herrera-Varela M, Fillinger U, Lindsay SW. Water vapour is a pre-oviposition attractant for the malaria vector Anopheles gambiae sensu stricto. Malar J. 2013;12:365.

21. Eneh LK, Okal MN, Borg-Karlson A-K, Fillinger U, Lindh JM. Gravid Anopheles gambiae sensu stricto avoid ovipositing in Bermuda grass hay infusion and it's volatiles in two choice egg-count bioassays. Malar J. 2016;15:276.

22. Wondwosen B, Birgersson G, Seyoum E, Tekie H, Torto B, Fillinger U, et al. Rice volatiles lure gravid malaria mosquitoes Anopheles arabiensis. Sci Rep. 2016:6:37930.

23. Sumba LA, Guda TO, Deng AL, Hassanali A, Beier JC, Knols BGJ. Mediation of oviposition site selection in the African malaria mosquito Anopheles gambiae (Diptera: Culicidae) by semiochemicals of microbial origin. Int $J$ Trop Insect Sci. 2004:24:260-5.

24. Bøgh C, Clarke SE, Jawara M, Thomas CJ, Lindsay SW. Localized breeding of the Anopheles gambiae complex (Diptera: Culicidae) along the River Gambia, West Africa. Bull Entomol Res. 2003:93:279-87.

25. Mwangangi JM, Shililu J, Muturi EJ, Muriu S, Jacob B, Kabiru EW, et al. Anopheles larval abundance and diversity in three rice agro-village complexes Mwea irrigation scheme, central Kenya. Malar J. 2010;9:228.

26. Imbahale SS, Paaijmans KP, Mukabana WR, van Lammeren R, Githeko AK, Takken W. A longitudinal study on Anopheles mosquito larval abundance in distinct geographical and environmental settings in western Kenya. Malar J. 2011;10:81.

27. Ndenga BA, Simbauni JA, Mbugi JP, Githeko AK, Fillinger U. Productivity of malaria vectors from different habitat types in the western Kenya highlands. PLOS ONE. 2011;6:e19473.

28. Fillinger U, Sombroek H, Majambere S, van Loon E, Takken W, Lindsay SW. Identifying the most productive breeding sites for malaria mosquitoes in The Gambia. Malar J. 2009;8:62.

29. Minakawa N, Dida GO, Sonye GO, Futami K, Njenga SM. Malaria vectors in Lake Victoria and adjacent habitats in western Kenya. PLoS ONE. 2012;7:e32725.

30. Gillies MT, DeMeillon B. The Anophelinae of Africa south of the Sahara (Ethiopian zoogeographical region). South Afr Inst Med Res. 1968;4:1-343.

31. Dia I, Guelbeogo MW, Ayala D. Advances and perspectives in the study of the malaria mosquito Anopheles funestus. In: Manguin Sylvie, editor. Anopheles mosquitoes new insights into malar vectors. London: InTech. 2013.

32. Asmare $Y$, Hopkins RJ, Tekie H, Hill SR, Ignell R. Grass pollen affects survival and development of larval Anopheles arabiensis (Diptera : Culicidae). J Insect Sci. 2017;17:1-8.

33. Ye-ebiyo Y, Pollack RJ, Kiszewski A, Spielman A. Enhancement of development of larval Anopheles arabiensis by proximity to flowering maize (Zea mays) in turbid water and when crowded. Am J Trop Med Hyg 2003;68:748-52.

34. Ye-ebiyo Y, Pollack RJ, Spielman A. Enhanced development in nature of larval Anopheles arabiensis mosquitoes feeding on maize pollen. Am J Trop Med Hyg. 2000;63:90-3.

35. Merritt RW, Dadd RH, Walker ED. Feeding behavior, natural food, and nutritional relationships of larval mosquitoes. Annu Rev Entomol. 1992;37:349-74.

36. Conchou L, Lucas P, Meslin C, Proffit M, Staudt M, Renou M. Insect odorscapes: from plant volatiles to natural olfactory scenes. Front Physiol. 2019;10:972.

37. Bruce TJA, Wadhams $L$, Woodcock CM. Insect host location: a volatile situation. Trends Plant Sci. 2005;10:269-74.

38. Bruce TJA, Pickett JA. Perception of plant volatile blends by herbivorous insects_-finding the right mix. Phytochemistry. 2011;72:1605-11.

39. Nyasembe VO, Torto B. Volatile phytochemicals as mosquito semiochemicals. Phytochem Lett. 2014;8:196-201.
40. Bokore GE, Ouma P, Onyango PO, Bukhari T, Fillinger U. A cross-sectional observational study investigating the association between sedges (swamp grasses, Cyperaceae) and the prevalence of immature malaria vectors in aquatic habitats along the shore of Lake Victoria, western Kenya. F1000Res. 2020;9:1032.

41. Eneh LK, Saijo H, Borg-Karlson A-K, Lindh JM, Rajarao GK. Cedrol, a malaria mosquito oviposition attractant is produced by fungi isolated from rhizomes of the grass Cyperus rotundus. Malar J. 2016;15:478.

42. Asmare $Y$, Hill SR, Hopkins RJ, Tekie H, Ignell R. The role of grass volatiles on oviposition site selection by Anopheles arabiensis and Anopheles coluzzii. Malar J. 2017;16:65.

43. Wondwosen B, Hill SR, Birgersson G, Seyoum E, Tekie H, Ignell R. A(maize) ing attraction: gravid Anopheles arabiensis are attracted and oviposit in response to maize pollen odours. Malar J. 2017;16:39.

44. Wondwosen B, Birgersson G, Tekie H, Torto B, Ignell R, Hill SR. Sweet attraction: sugarcane pollen-associated volatiles attract gravid Anopheles arabiensis. Malar J. 2018;17:1-9.

45. Simpson DA, Yesson C, Culham A, Couch CA, Muasya AM. Climate change and Cyperaceae. London: Cambridge University Press; 2011.

46. Reznicek AA. Cyperaceae . Britannica. 2013. https://www.britannica.com/ plant/Cyperaceae/Evolution-and-classification. Accessed 20 Mar 2021.

47. Dida GO, Anyona DN, Abuom PO, Akoko D, Adoka SO, Matano AS, et al. Spatial distribution and habitat characterization of mosquito species during the dry season along the Mara River and its tributaries, in Kenya and Tanzania. Infect Dis Poverty. 2018;7:1-16.

48. Gfeller A, Laloux M, Barsics F, Kati DE, Haubruge E, du Jardin P, et al. Characterization of volatile organic compounds emitted by barley (Hordeum vulgare $\mathrm{L}$.) roots and their attractiveness to wireworms. J Chem Ecol. 2013;39:1129-39.

49. Fatouros NE, Lucas-barbosa D, Weldegergis BT, Pashalidou FG, Van JJA, Dicke $M$, et al. Plant volatiles induced by herbivore egg deposition affect insects of different trophic levels. PLOS ONE. 2012;7:e43607.

50. Olawore NO, Usman LA, Ogunwande IA, Adeleke KA. Constituents of rhizome essential oils of two types of Cyperus articulatus L. grown in Nigeria. J Essent Oil Res. 2006;1 8:604-6.

51. Okal MN, Herrera-Varela M, Ouma P, Torto B, Lindsay SW, Lindh JM, et al. Analysing chemical attraction of gravid Anopheles gambiae sensu stricto with modified BG-Sentinel traps. Parasit Vectors. 2015:8:301.

52. Herrera-Varela M, Lindh J, Lindsay SW, Fillinger U. Habitat discrimination by gravid Anopheles gambiae sensu lato-a push-pull system. Malar J. 2014;13:133.

53. Hayes RJ, Bennett S. Simple sample size calculation for cluster-randomized trials. Int J Epidemiol. 1999;28:319-26.

54. Okal MN, Lindh JM, Torr SJ, Masinde E, Orindi B, Lindsay SW, et al. Analysing the oviposition behaviour of malaria mosquitoes: design considerations for improving two-choice egg count experiments. Malar J. 2015;14:250

55. R Core Team. R: A language and environment for statistical computing. Vienna: R Foundation for Statistical Computing; 2020.

56. Raguso RA, Pellmyr O. Dynamic headspace analysis of floral volatiles: a comparison of methods. Oikos. 1998:81:238-54.

57. Deletre E, Chandre F, Williams L, Duménil C, Menut C, Martin T. Electrophysiological and behavioral characterization of bioactive compounds of the Thymus vulgaris, Cymbopogon winterianus, Cuminum cyminum and Cinnamomum zeylanicum essential oils against Anopheles gambiae and prospects for their use as bednet treatment. Parasit Vectors. 2015;8:316.

58. Nyasembe VO, Teal PE, Mukabana WR, Tumlinson JH, Torto B. Behavioural response of the malaria vector Anopheles gambiae to host plant volatiles and synthetic blends. Parasit Vectors. 2012;5:234.

59. Nyasembe VO, Tchouassi DP, Pirk CWW, Sole CL, Torto B. Host plant forensics and olfactory-based detection in Afro-tropical mosquito disease vectors. PLoS Negl Trop Dis. 2018;12:e006185.

60. Meza FC, Roberts JM, Sobhy IS, Okumu FO, Tripet F, Bruce TJA. Behavioural and electrophysiological responses of female Anopheles gambiae mosquitoes to volatiles from a mango bait. J Chem Ecol. 2020;46:387-96.

61. Nyasembe VO. Nectar feeding and volatile chemical signatures influencing host plant selection in major Afrotropical mosquito disease vectors. University of Pretoria. 2016.

62. Tholl D, Boland W, Hansel A, Loreto F, Röse USR, Schnitzler JP. Practical approaches to plant volatile analysis. Plant J. 2006;45:540-60. 
63. Kfoury N, Scott E, Orians C, Robbat A. Direct contact sorptive extraction: a robust method for sampling plant volatiles in the field. J Agric Chem. 2017;65:8501-9.

64. Kigathi RN, Unsicker SB, Reichelt M, Kesselmeier J, Gershenzon J, Weisser WW. Emission of volatile organic compounds after herbivory from Trifolium pratense ( L.) under laboratory and field conditions. J Chem Ecol. 2009;35:1335-48.

65. Stewart-Jones A, Poppy GM. Comparison of glass vessels and plastic bags for enclosing living plant parts for headspace analysis. J Chem Ecol. 2006:32:845-64.

66. Gouinguene SP, Turlings TCJ. The effects of abiotic factors on induced volatile emissions in corn plants. Plant Physiol. 2002;129:1296-307.

67. Reichstein M. Controls on the emission of plant volatiles through stomata: a sensitivity analysis. J Geophys Res Atmos. 2003;108:1-10.

68. Assmann SM, Snyder J, Lee Y-RJ. ABA-deficient (aba1) and ABA-insensitive (abi1-1, abi2-1) mutants of Arabidopsis have a wild-type stomatal response to humidity. Plant Cell Environ. 2000;23:387-95.

69. Kigathi RN, Weisser WW, Reichelt M, Gershenzon J, Unsicker SB. Plant volatile emission depends on the species composition of the neighboring plant community. BMC Plant Biol. 2019;19:58

70. Lahondère C, Vinauger C, Okubo RP, Wolff GH, Chan JK, Akbari OS. The olfactory basis of orchid pollination by mosquitoes. Proc Natl Acad Sci USA. 2020;117:708-16.

71. Nyasembe VO, Tchouassi DP, Kirwa HK, Foster WA, Teal PEA, Borgemeister C, et al. Development and assessment of plant-based synthetic odor baits for surveillance and control of malaria vectors. PLOS ONE. 2014;9:1-10.

72. Knudsen JT, Eriksson R, Gershenzon J, Ståhl B. Diversity and distribution of floral scent. Bot Rev. 2006;72:1-120.

73. Eisenreich W, Schwarz M, Cartayrade A, Arigoni D, Zenk MH, Bacher A. The deoxyxylulose phosphate pathway of terpenoid biosynthesis in plants and microorganisms. Chem Biol. 1998;5:R221-33.

74. Schwab W, Davidovich-Rikanati R, Lewinsohn E. Biosynthesis of plantderived flavor compounds. Plant J. 2008;54:712-32.

75. Darshanee HLC, Ren H, Ahmed N, Zhang Z. Volatile-mediated attraction of greenhouse whitefly Trialeurodes vaporariorum to tomato and eggplant. Front Plant Sci. 2017;8:1-13.

76. Mayo P, Silk P, Abeysekera SD, Magee DI. Synthesis of three putative kairomones of the beech leaf-mining weevil synthesis of three putative kairomones of the beech leaf-mining weevil Orchestes fagi (L.). Synth Commun. 2016:46:1124-32.

77. Miao C, Li W, Dong S, Luo Q, Zhao M, Guo X. A chemical basis for different oviposition rates of Helicoverpa assulta across two Nicotiana species. Arthropod Plant Interact. 2020;14:705-16.

78. Asui HY, Asuda TY, Ukaya MF, Kino TA, Akamura SW, Irai YH, et al. Host plant chemicals serve intraspecific communication in the white-spotted longicorn beetle, Anoplophora malasiaca (Thomson) (Coleoptera: Cerambycidae). Appl Entomol Zool. 2007:42:255-68.

79. Zhang Y, Wang R, Yu L, Lu P, Luo Y. Identification of Caragana plant volatiles, overlapping profiles, and olfactory attraction to Chlorophorus caragana in the laboratory. J Plant Interact. 2015;10:41-50.

80. Meng X, Hu J, Li Y, Dai J, Ouyang G. Screening for effective odors through which Conopomorpha sinensis Bradley (Lepidoptera: Gracillariidae) locates its host. Chemoecology. 2021:31:301-10.

81. Jaleta KT, Hill SR, Birgersson G, Tekie H, Ignell R. Chicken volatiles repel host-seeking malaria mosquitoes. Malar J. 2016;15:354.

82. Beehler JW, Millar JG, Mulla MS. Synergism between chemical attractants and visual cues influencing oviposition of the mosquito, Culex quinquefasciatus (Diptera: Culicidae). J Chem Ecol. 1993;19:635-44.
83. Gibson G. A behavioural test of the sensitivity of a nocturnal mosquito, Anopheles gambiae, to dim white, red and infra-red light. Physiol Entomol. 1995:20:224-8.

84. Wellington WG. Changes in mosquito flight associated with natural changes in polarized light. Can Entomol. 1974;106:941-8.

85. Silberglied RE. Communication in the ultraviolet. Ann Rev Ecol Syst. 1979;10:373-98.

86. Njoroge MM, Fillinger U, Saddler A, Moore S, Takken W, van Loon JJA, et al. Evaluating putative repellent 'push' and attractive 'pull' components for manipulating the odour orientation of host-seeking malaria vectors in the peri-domestic space. Parasit Vectors. 2021;14:42.

87. Database GIS. Species profile: Cenchrus setaceus. 2021. http://www.iucng isd.org/gisd/species.php?sc=309. Accessed 19 May 2021.

88. CABI. Panicum repens (torpedo grass): In Invasive Species Compendium. 2019. https://www.cabi.org/isc/datasheet/38670\#tosummaryOfInvasiven ess. Accessed 19 May 2021.

89. Beck P, Jennings J, Rogers J. Management of pastures in the upper south: the I-30 and I-40 corridors. Manag Strateg Sustain Cattle Prod South Pastures. 2019;189-26.

90. Rojas-Sandoval J, Acevedo-Rodríguez P. Cynodon dactylon (Bermuda grass). 2019. https://www.cabi.org/isc/datasheet/17463\#5BBAF39A-F2124CE5-89B9-ED1516EEE06F. Accessed 19 May 2021.

91. Pl@ntNet. Cyperaceae-Cyperus exaltatus Retz.: In Riceweeds en. http:// publish.plantnet-project.org/project/riceweeds_en/collection/colle ction/information/details/CYPEX. Accessed 19 May 2021.

92. Kweka EJ, Owino EA, Mwang BJ, Mahande AM, Nyindo M, Mosha F. The role of cow urine in the oviposition site preference of culicine and Anopheles mosquitoes. Parasit Vectors. 2011;4:184.

93. Lindh JM, Nnaste A, Knols BGJ, Faye I, Borg-Karlson A-K. Oviposition responses of Anopheles gambiae s.s.(Diptera : Culicidae) and identification of volatiles from bacteria-containing solutions. J Med Entomol. 2008;45:1039-49.

94. Huang J, Walker ED, Vulule J, Miller JR. The influence of darkness and visual contrast on oviposition by Anopheles gambiae in moist and dry substrates. Physiol Entomol. 2007;32:34-40.

95. Mwingira VS, Spitzen J, Mboera LEG, Torres-Estrada JL, Takken W. The influence of larval stage and density on oviposition site-selection behavior of the Afrotropical malaria mosquito Anopheles coluzzii (Diptera: Culicidae). J Med Entomol. 2019;57:657-66.

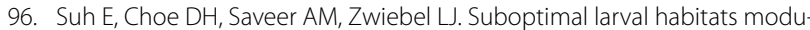
late oviposition of the malaria vector mosquito Anopheles coluzzii. PLoS ONE. 2016;11:1-20

97. Gouagna LC, Rakotondranary M, Boyer S, Lempérière G, Dehecq JS, Fontenille D. Abiotic and biotic factors associated with the presence of Anopheles arabiensis immatures and their abundance in naturally occurring and man-made aquatic habitats. Parasit Vectors. 2012;5:96.

\section{Publisher's Note}

Springer Nature remains neutral with regard to jurisdictional claims in published maps and institutional affiliations.

Ready to submit your research? Choose BMC and benefit from:

- fast, convenient online submission

- thorough peer review by experienced researchers in your field

- rapid publication on acceptance

- support for research data, including large and complex data types

- gold Open Access which fosters wider collaboration and increased citations

- maximum visibility for your research: over 100M website views per year

At BMC, research is always in progress.

Learn more biomedcentral.com/submissions 